\title{
Acerca das posições de Portugal na Europa e no Mundo / Crónicas independentes de Lisboa
}

\section{Pedro S. Germano}

Doutor em Estudos Portugueses pela Sorbonne, Paris IV

\section{Resumo}

O ensaio aborda a degradação exponencial das relações entre Estados, Federações, Uniões e simples Associações, todos esses conjuntos muito ocupados em dar seguimento ao diktat das potências dominantes. Aponta como perspectiva um desafio que só o futuro poderá melhor esclarecer, mas Portugal não poderá se escudar nas boas medidas e intenções da diplomacia europeia que tal como nas questões sociais e económicas está apta sim, mas para a aplicação e defesa dos seus próprios princípios directores.

Palavras-chave: Portugal, diplomacia europeia, economia portuguesa.

\section{Abstract}

The essay addresses the exponential degradation of relations between states, federations, unions and simple associations, all these sets too busy to continue the diktat of the ruling powers. Perspective points as a challenge that only the future can clarify, but Portugal cannot hide behind the good measures and intentions of European diplomacy such as social and economic issues but rather is able to apply and defend their own guiding principles.

Key words: Portugal, European diplomacy, Portuguese economics

\section{Resumen}

El ensayo aborda la degradación exponencial de las relaciones entre estados, federaciones, sindicatos y asociaciones simples, todos estos conjuntos demasiado ocupado para seguir los dictados de las potencias dominantes. Puntos perspectiva como un reto que sólo el futuro puede aclarar, pero Portugal no puede esconderse detrás de las buenas intenciones y la acción de la diplomacia europea, tales como las cuestiones sociales y económicas, sino que es capaz de aplicar y defender sus propios principios rectores.

Palabras clave: Portugal, diplomacia europea, economía portuguesa

\section{I - Em torno das tendências neoliberais na Europa e no mundo "globalizado"}

Nada disto é novidade, a não ser a constatação da existência de um movimento acelerado, diria talvez descontrolado que os grandes grupos de pressão política e económica têm implacável, sistemática e sofisticadamente imposto. 
Uma agravante bem visível é a tendência para que as forças económicas e financeiras se imponham às políticas internas de cada Estado, condicionando-as; fazem-no às claras e impunemente, de tal modo que os Estados ficaram subjugados pelas exigências dos grandes grupos capitalistas que neste novo patamar de liberalismo se impuseram e actuam com a técnica dos parasitas insaciáveis. Assim, não há economia e base política de cariz democrático de uma nação que consiga sobreviver, muito menos impor-se.

Tais grupos de pressão têm assumido funções de vicariedade da própria estrutura legislativa soberana dos vários Estados Conseguiram inclusive criar tribunais internacionais cujas decisões se impõem à legislação que deveria ser soberana de cada Estado. Por outras palavras, esses tribunais criados e financiados pelas grandes estruturas economicistas privadas colocam os Estados Soberanos em posição subalterna e não há força suficiente destes para escapar a tal armadilha.

Exemplos? Só não os aborda quem o não quiser: vejamos, embora em dimensões e condicionalismos diferentes, os recentíssimos casos da situação da Grécia, da asfixia financeira com que ela é confrontada; citemos ainda os efeitos do mesmo modo asfixiantes para algumas economias em relação à cotação de algumas matérias-primas, designadamente a dos combustíveis. Por fim, a corrupção instalada ao mais alto nível dos sistemas governativos com extensões ao controlo e desejada gestão das economias nacionais.

Qual será a "democracia” actual que não sofra a asfixia causada por estas "ervas daninhas"? Quem terá poderes no tempo e no espaço para as erradicar eficazmente?

Com as frequentes oscilações, bruscas e negativas, dos preços das matérias primas e dos financiamentos cegos se obrigam as economias / as políticas dos Estados a entrarem em colapso. Estou a referir-me, por exemplo, aos casos da produção de petróleo em Angola e na Rússia.

\section{II - A globalização como força transversal}

Esta nova tendência da política mundial vai-se socorrendo das estruturas desenvolvidas especialmente durante o período da "guerra fria”. Não há nada mais desestabilizador e devastador do que ela que invade as antigas estruturas dos Estados (certamente às vezes desadaptadas, porque arcaicas) e vai proporcionar o desequilíbrio das economias e dos grupos humanos.

A questão é que todas as regiões do Mundo se têm baseado e aproveitado dessa orientação para justificarem medidas de expansão, ou de proteccionismo num mundo sem regras senão a do grande e triunfante capital.

A propalada globalização levou algumas nações a reagruparem as antigas regiões chegando recentemente, por exemplo, a instaurar um Estado dito islâmico por uma área que de influência tendencialmente estendida desde a Península Ibérica até ao Irão e à Índia, passando pelo norte de África, um pouco à imitação do espaço antigamente controlado pelo extinto império otomano.

A desregulação do antigo direito internacional é tão grande que os países da área da chamada "democracia ocidental" não encontram caminho de oposição eficaz a essa "nação" / "império” nascente.

\section{III - O reordenamento da Europa}


A organização do grande espaço europeu, após a II ${ }^{a}$ guerra, foi, no seu ponto de partida mais conhecida por Conselho da Europa, já em 1949: logo a seguir as tendências unionistas resultaram na criação em 1951 da Comunidade do Carvão e do Aço (C. E. C. A.) com base nos interesses económicos de seis países, tendo o Tratado de Roma, em 1957 configurado o marco mais importante desse movimento inicial, ficando definida a C. E. E (Comunidade Econômica Europeia).

Nessas decisões tomadas pouco tempo depois do final da II a guerra, se vê que a dita "união" ficou essencialmente ligada à força e interdependência económica dos países membros; depois, o facto de se lhe ter adicionado a componente da memória da grande unidade, força e brilho do antigo império romano e da necessidade de encontrar para a Europa uma solução que evitasse definitiva e pacificamente uma saída que não a do claramente infeliz recurso às guerras fratricidas dos séculos XIX e XX. Tratou-se de uma medida que poderíamos classificar de tonalidade romântica, naquele sentido em que o movimento romântico do início do séc. XIX foi uma força impulsionadora de algumas independências no Próximo Oriente e até na América Central e do Sul. Tais novos países foram no caso da Europa e de alguns países do Mediterrâneo, conseguindo a independência à custa da desagregação do império otomano, tendo daí nascido em tempos e ritmos diferentes países como a Grécia, o Líbano, a Palestina, etc., a cuja evolução nem sempre linear assistimos a partir dos finais da II a guerra mundial.

Claramente se descobre que as potências europeias que hoje dominam os grandes centros de decisão europeus - mas mantendo relações capciosas (nada independentes?) com os centros de decisão internacionais - são exactamente as mesmas que estiveram na origem das grandes matanças europeias (com algum sangue exterior - mas não assim tão inocente - à mistura) são as mesmas que hoje dão cartas à sempre em causa união europeia: bastaria relembrar o momento das guerras napoleónicas, da tentativa de imposição da Alemanha, já nos finais do séc. XIX (na Europa e no mundo das colónias: quem não se recorda da célebre Conferência de Berlim (1884-1885)?) e das grandes chacinas da $1^{\text {a }}$ Grande Guerra e pouco depois na IIa.

Foram os ideais românticos que percorreram e impulsionaram o movimento dos grandes países europeus dominantes, a França e a Inglaterra, na luta de alguns países contra o poder otomano; a Alemanha não seguiu esse caminho expansionista expansão tão evidente porque às vezes foi vencida naqueles conflitos europeus e mundiais; mesmo quanto ao império otomano, ela assumiu o papel de aliada como se documenta nas duas últimas grandes guerras.

Assim se constatou que a unificação da Europa se preparou e executou essencialmente com base na organização do espaço dominado até 476 pelo antigo Império Romano do Ocidente; no Oriente beneficiou da decadência do império otomano e da falta de unidade dos países árabes na Ásia e do Norte de África. A questão da unidade do mundo arabo-muçulmano não deve ser colocada sem reservas ao lado da política turca uma vez que entre árabes e turcos otomanos se manteve durante longos períodos um estado de guerra latente com consequências irreversíveis para a actual correlação de forças em todo o Médio Oriente, no Norte de África.

No caso do alargamento da C. E. no último quartel do século $\mathrm{XX}$ aos dois países da Península Ibérica, especialmente a Portugal, são significativas a cronologia e as condições em que a adesão se processou. Houve de tudo, incluindo o recurso ao financiamento e implementação de medidas de livre circulação de pessoas e bens de 
forma sorrateira porque iniciadas avant la lettre. Toda a panóplia de ajudas financeiras se conjugou e quase sempre precedeu o acto solene de adesão.

Pior, tal adesão à C. E. nunca foi submetida a referendo, podendo assim classificar-se de não democrática. Foi sim, só para falar de Portugal, um acto do governo do então $1^{\circ}$ ministro Cavaco Silva (PSD) exercendo o poder em tandem marcadamente político com Mário Soares (PS), este então na Presidência da República.

Foi notório que o $1^{\circ}$ ministro dessa época (hoje PR a completar dez anos de funções!) se vangloriava de em cada dia estarem a entrar milhares / milhões (conforme a unidade monetária) no país. Os portugueses nunca foram bem informados sobre as contrapartidas que ele foi obrigado / condicionado (?!) a assumir perante as estruturas da C, B. e que mais tarde se revelaram duramente perniciosas para a saúde económica e cultural do país.

Isto só para sublinhar a afirmação supra de que as medidas e condicionalismos económicos e financeiros constituíram o suporte da política partidária e governativa portuguesa durante o largo período das "benesses" (?) de alargamento da C.E.

Pela calada, muitos portugueses diziam: não fomos nós que entrámos na Europa; ela é que entrou em nós; a um francês que nessa fase me perguntou se estava contente / de acordo com a entrada na C.E., respondi-lhe com a tradicional fábula portuguesa acerca do passeio pelo campo de duas panelas, uma de barro e outra de ferro. Todos conhecem ou pelo menos podem imaginar as consequências.

A situação agravou-se mais um grau com a substituição do Escudo pelo Euro: ela consolidou as desigualdades económicas entre os países do Norte e os do Sul, numa marcha que desembocou (embora não seja a sua única responsável) na crise económica, financeira e social que acabámos de viver neste início do corrente milénio e que ainda continuará, mas até quando?

\section{IV - A evolução da situação política em Portugal após o 25 de Abril de 1974}

Como se acaba de dizer, a adesão à C. E. (em 1995 de 13 países membros) nunca foi democraticamente sufragada, sendo confrangedor o à-vontade como os políticos portugueses através dos seus dirigentes se movimentam dentro dos ideais que a revolução do 25 de Abril defendeu e pretendeu alargar a toda a sociedade. Isto porque num momento inicial de euforia revolucionária, as classes trabalhadoras conseguiram fazer valer as suas reivindicações sem deixarem de estar integradas num sistema económico tradicional.

Como a minha idade me permitiu assistir à evolução das "peças do xadrez" político e às tendências sociais, políticas e económicas, pudemos constatar as diversas etapas, todas elas no sentido de esvaziar o espírito do Portugal pós-Salazar/Caetano: a primeira travagem ou desvio da dominante livre/socialista/tipo revolucionário, por vezes ingénua, fixou-se nos resultados das primeiras eleições presidenciais livres na sequência da aprovação da nova Constituição da República. Foi evidente que a eleição do candidato general Ramalho Eanes, militar que tinha liderado e vencido a luta contra as forças e movimentos mais próximos da chamada esquerda, deu por encerrado o chamado "verão quente" de 1975 e inflectiu para a direita toda a política nacional; a segunda intervenção visível das tendências tradicionalistas consistiu na cisão do colectivo militar, o chamado Conselho da Revolução. Nele formou-se e 


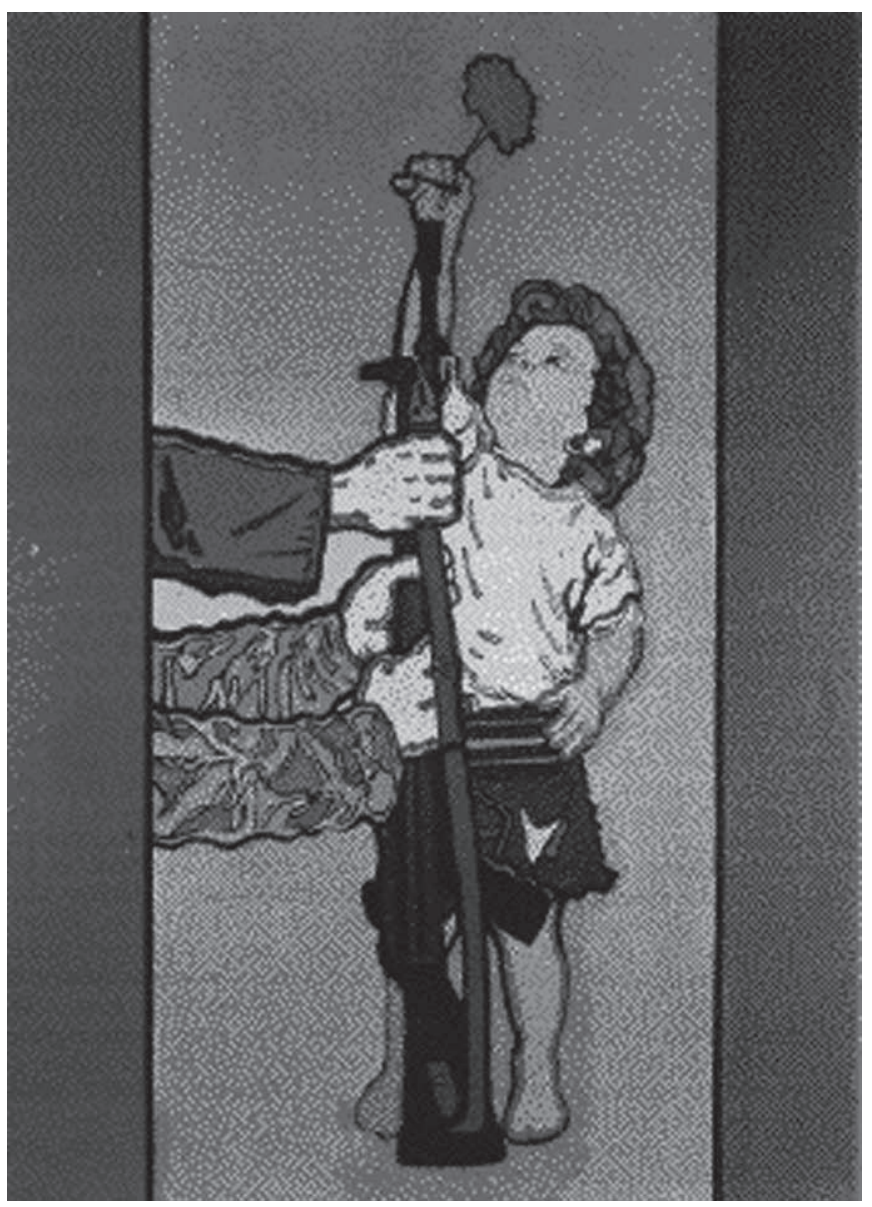

Cartaz da Revolução dos Cravos, 1974. Sérgio Guimarães.

impôs-se uma espécie de "ala liberal" que ficou conhecida por Grupo dos Nove. $\underline{A}$ terceira cunha no processo democrático da revolução do 25 de Abril verificou-se no domínio do movimento sindical que até então era unitário. Nesse momento foi dada figura jurídica a una nova central sindical, a UGT que no início não passava de uma figura jurídica para a qual as forças de direita transferiram as capacidades de diálogo/ negociação que na prática só deveriam estar na CGTP-Intersindical. Houve a seguinte justificação-slogan repetido à saciedade: «a CGTP é uma "correia de transmissão" do PCP.». A quarta consistiu no ataque em diversas frentes contra a Reforma Agrária e a outras associações saídas directamente do período revolucionário: foram sempre frentes sociais manipuladas pelos partidos da direita e com aplicação de restrições ao normal funcionamento das associações, das cooperativas. Por detrás desses ataques estava outro slogan mil vezes escutado: «é preciso quebrar a espinha dorsal do PCP.»

Dado que a partir dos finais da década de setenta, o poder já estava nas mãos das forças que tinham apoiado a eleição do PR Ramalho Eanes e mesmo o $1^{\circ}$ ministro Mário Soares já se tinha demitido, as forças tradicionalistas aproveitaram para proceder a uma primeira revisão constitucional com o objetivo conseguido de dar por findo o Conselho da Revolução pela simples razão de que ele ainda era o guardião dos ideais do 25 de Abril (apesar do grande cisma do referido "Grupo dos Nove"). Essa alteração visava sobretudo à supressão de qualquer obstáculo à implementação das políticas liberais, agora com o "estafado" argumento de que o Conselho da Revolução" não era uma instituição rigorosamente democrática (=não tinha sido sufragada por 
eleições livres), mas esquecendo-se/omitindo que foram precisamente os militares de Abril quem abriu as portas à democracia pluralista!

Sub-repticiamente foram desencantar velhas personalidades afectas ao período da ditadura salazarista e guindaram-nas aos mais altos postos do Estado. Não as vou enumerar todas, mas é significativo que figuras como alguns militantes do CDS (este partido já tinha votado contra a Constituição de 1975) e do PSD tenham sucessivamente ocupado cargos ministeriais de relevo. Não se pode esquecer que o actual Presidente da República já tinha sido primeiro-ministro durante dois mandatos e actualmente completa o segundo e último quinquénio como Chefe de Estado. Dele ficam pormenores de comportamento e de decisões que umas vezes se poderiam classificar como escabrosos e outras por folclóricos; não resisto à longamente difundida ficha de inscrição como informador da PIDE, num impresso oficial, com fotografia e tudo; como "folclore", destacam-se alguns comportamentos e manifestações de desconhecimento da cultura portuguesa profunda.

Muitas vezes me questiono sobre as perniciosas consequências da ocupação do aparelho do Estado democrático por pessoas com estrutura e passado fascista! Como foi possível a um "pidesco" confesso estar à frente dos destinos de um país saído da revolução de Abril? O mínimo que lhe deveria ser exigido é que desmentisse sem rodeios a evidência publicitada!

À invasão das estruturas de cúpula do Estado foi acompanhada pelo renascimento e influência de duas já antigas organizações secretas, embora de sinais algo diferentes. No entanto elas convergiram no caminho da ocupação e peso das citadas estruturas do Estado servindo ambas para barrar as portas a todos os que não se enquadravam nos seus "gostos", ou simplesmente "pondo-os na prateleira", ou expulsando-os, para tal usando os mais diversos estratagemas: estou a falar das muitas centenas de membros da maçonaria e da Opus Dei, desde o P. R. até a alguns ministros, secretários de Estado e altos funcionários. Das suas influências no aparelho Estado poderíamos longamente falar. Uma coisa posso adiantar: entre os membros do Estado após o 25 de Abril, poucos haverá que não tenham pertencido, nem militado numa dessas duas instituições secretas. São eles que serviram de veículos - e de que maneira! - à implementação das políticas mais liberais. Sabe-se inclusive que alguns deles vieram directamente de famílias que exerceram grandes influências e funções governativas na fase final do liberalismo do século XIX. Nessa época, em plena euforia liberal, ficou célebre o tandem de dois partidos que governaram alternadamente o país entre 1878 e 1891. Esse sistema ficou conhecido por "rotativismo", solução que se tem praticamente transferido para os últimos trinta a quarenta anos no agora designado "arco da governação" em que alternam o PSD e o PS, embora com um ou outro pequeno partido acoplado para efeitos de maioria parlamentar.

Se praticamente estou a repetir as informações supra é porque as medidas liberais dos últimos governos do PSD e do PS em pouco se afastam das que se aplicaram desastradamente naquela fase dos finais da monarquia constitucional e, como também dito, pelos antepassados da tradição liberal que se sabe ter conduzido o país a situações muito críticas.

Perante outras mais modernas associações, agrupamentos e instituições, algumas delas de forte implantação mundial, que dizer, por exemplo, do famigerado Club de Bielderberg do qual faz parte um antigo primeiro ministro do PSD e certamente outras personalidades da actual vida pública portuguesa? 
As clivagens iniciais entre as forças ditas "progressistas” afectas aos ideais de Abril e as mais tradicionalistas, foram-se acentuando pouco a pouco e percorreram caminhos nem sempre claros. Assim, a economia foi empurrada para um colapso o qual se agudizou pela "machadada final" da adesão ao sistema monetário do euro que nós consideramos uma novíssima arma de destruição maciça ao serviço da potência bem conhecida por Alemanha que assim se renova substituindo o seu arsenal imperial e colonial: colonial, a partir da Conferência de Berlim (1884-1885) e imperial desde também o século XIX até ao II Reich, pelo menos.

É neste contexto europeu (deveríamos dizer tendencialmente alemão, com todas as implicações...) que se coloca a questão do relacionamento do novo Portugal com espaço europeu, com o dos países lusófonos e com a comunidade internacional.

\section{V - Visão crítica da evolução da actual situação política e socioeconómica}

Como pano de fundo, teremos sempre o mundo da grande corrupção generalizada e protegida até pelo aparelho do Estado (essas coisas não acontecem só no Brasil!...), o eterno quebra-cabeças da deficiente aplicação da justiça, dos atropelos à vida democrática e das malfeitorias do sistema financeiro todo poderoso e opressor das camadas trabalhadoras, o mesmo será dizer de todo o país. Pelo meio, toda a gama de escândalos ao nível da vida local e da alta finança que reúne o mais devastador exemplo na recente falência logo seguida de venda fraudulenta de estabelecimentos bancários e também do património do Estado, desde o Banco Privado Português, passando pelo Banco Português de Negócios até ao Banco Espírito Santo, este último ainda em fase conclusiva, mas sempre com prejuízo para o Estado, o mesmo será dizer para todos os contribuintes e todas as actividades económicas.

Claro que no meio de compadrios que certamente geram a corrupção ao mais alto nível. Os actos de corrupção chegam a ser identificados, julgados e punidos pelos tribunais estrangeiros, mas em Portugal são arquivados. A este respeito basta citar o caso das condições de aquisição de submarinos na Alemanha e de "luvas" e contrapartidas verificadas no contrato em que o actual Vice-Primeiro Ministro foi ministro da Marinha. Claro que nos media aparece com frequência o caso do ex-Primeiro-Ministro, José Sócrates, preso sem culpa formada há mais de seis meses. Não pretendo de modo nenhum imiscuir-me nas questiúnculas da propalada culpa, nem na necessidade de evitar a destruição de provas para o julgamento que começa a aparecer adiado sine dia, isto é, à primeira vista esse processo de um rigor inusitado para um hipotético arguido (em contraste flagrante com outros casos de corrupção cujos presumíveis responsáveis gozam da mais completa liberdade e até de elogios públicos), tudo isso tem contribuído para aumentar a "cortina de fumo" que nos dificulta de chegar a conclusões claras e isentas.

Onde está a igualdade do cidadão perante a lei?

Passamos à análise separada de alguns quatro itens à volta de questões de grande impacto económico:

a) Situação económica de grande fatia da população;

b) Parcerias Público Privadas;

c) Propostas para obstar às dificuldades inerentes à actual situação económica;

d) Efeitos dos tratados internacionais 


\section{a) Situação económica de grande parte da população}

Além de condições económicas deficientes, verificam-se muitos casos de desemprego, sobretudo entre os jovens e a classe etária de mais de quarenta anos. Outra camada da população tem vivido das suas reformas (aposentadorias), mas estas têm estado sob a mira obsessiva do governo que as reduz e taxa a níveis nunca imaginados, muito menos previstos pela legislação em vigor no momento de acesso à reforma (aposentação).

Se abordo este último pormenor é porque ele é transversal à sociedade e esse tema é recorrente em períodos eleitorais como o que agora se aproxima: os políticos falam muito da «sustentabilidade do sistema de reformas» mas esquecem-se quase sempre de falar da necessidade de promover uma melhor gestão dos correspondentes fundos de pensão e das razões pelas quais os montantes das reformas no sector privado foram / são diferentes dos verificados no sector público. Para o actual governo, a solução milagrosa seria a «convergência das pensões» de modo a que as do sistema público ficassem equiparadas às dos sistemas privados.

No domínio do sector público, há a noção bem difundida de que as condições de acesso ao fundo público de pensões não foram sempre equitativamente levadas em conta, havendo pensionistas que tiveram um curtíssimo tempo de desconto para a aposentação e mesmo assim a sua reforma é muitas vezes superior à daquelas que descontaram durante dezenas de anos para terem direito a um montante condigno. Pior, há pensionistas do sector público a quem foi atribuído o direito à reforma baseada em legislação muito diferente dos casos gerais, o que leva à consideração de que a Caixa Geral de Aposentações funciona como uma espécie de caixote do lixo onde se acumulam todos os casos excepcionais. Entre as excepções ainda há as fraudes, os documentos falsos de muitos pensionistas, situação que se agravou em certos períodos como nos anos da descolonização (1974-1975) durante o qual sabemos que houve alguns casos de documentação falsa.

A esta dificuldade adicionam-se os casos de gestão danosa dos fundos de pensão por um ou outro funcionário, constando que se verificaram aplicações de alto risco com perdas substanciais de capital nunca mais recuperado.

São tantos os casos excepcionais que não será sem injustiça que se chegará a um cálculo que permita a tal «sustentabilidade».

O princípio da «convergência das pensões» até parece lógico. No entanto seria necessário que as condições de atribuição do valor da reforma fossem idênticas no sistema privado e no público. Porém verifica-se que no privado, os descontos para os fundos de pensões foram pelo menos algumas vezes efectuados a partir das declarações de vencimentos emitidas pelas entidades patronais em condições bem diversas das do sector público cujos valores de vencimento e pensões estavam definidos segundo a legislação aplicável cada ano. No privado foi política dos patrões declararem os descontos a partir de vencimentos abaixo dos valores oficiais, sendo o diferencial entregue particularmente (= "por baixo da mesa") ao trabalhador, não havendo assim lugar a descontos correspondentes para a Segurança Social. No entanto o trabalhador era compensado expressamente pelo patrão porque este também ficava a ganhar, uma vez que o nível de impostos que deveria entregar à Segurança Social era certamente 
mais baixo, resultado: perdia o trabalhador no montante da futura reforma e perdeu o Estado que não encaixou os devidos descontos.

Todos estes pormenores são questões de evidente falta de boa gestão da qual todos parecem alhear-se. Assim, "sem rei nem roque" não pode haver qualquer sustentabilidade, nem convergência justa de pensões.

\section{b) As parcerias público-privadas}

Designam-se normalmente pela sigla PPP, série de letras que o povo tem desenvolvido através da boutade (sê-lo-á?): o público paga ao privado, sistema que tem sido geral nos contratos entre o Estado e os privados. Estes costumam gabar-se de que o dinheiro das participações do Estado chega praticamente para pagar as obras e que o prazo estabelecido para a concessão das infraestruturas para gestão e cobrança de portagens, ou de outras taxas corresponde a um lucro obtido a partir dos fundos públicos com a vantagem de serem ressarcidos pelo mesmo Estado se os direitos a encaixar se situarem a níveis abaixo dos estabelecidos: é só lucro! Na prática, esta solução equivale à mera transferência de dinheiros públicos para os particulares, esquema que já se verificava na segunda metade do século XIX, tenho eu verificado as condições em que se executaram, por exemplo, as obras de construção da estação do Rossio.

Recentemente foram noticiados muitos casos de contratos (dessas parcerias) extremamente danosos para o erário público: tanto os governos do PSD como os do PS foram "useiros e vezeiros" nessas operações e o que se concluiu é que ninguém foi pessoalmente responsabilizado pelos danos causados aos cofres do Estado.

Verificaram-se inclusive algumas situações em que havendo organismos do Estado com aptidão e condições para gerir a aplicação dos dinheiros públicos, eles são ostensivamente postos de lado, o que resulta numa dupla despesa: aquele dinheiro que é pago aos privados que vão executar a obra e outro dinheiro que o Estado continua a desembolsar para os seus funcionários de campo, não mobilizados, e para a manutenção da maquinaria parada.

Situação idêntica se verifica em serviços públicos que têm um corpo de advogados à disposição, mas quando o Estado precisa de um parecer sobre qualquer interpretação legal, não é a eles que entrega a tarefa, mas sim a gabinetes de advogados particulares aos quais paga a "peso de oiro".

Nestes casos, nem sequer o Estado está simplesmente a pagar aos particulares; o Estado está sim a esbanjar o dinheiro dos contribuintes. Além disso, são situações que propiciam diversas facetas da corrupção: muitas vezes os próprios gabinetes de consultadoria são constituídos por advogados que ocupam, ou ocuparam recentemente o lugar de deputados da Assembleia da República e até por membros do governo, numa situação que roça pela promiscuidade...

Onde está a boa gestão?

\section{c) Debates sobre as soluções para as dificuldades resultantes da actual crise}

Têm sido organizados debates públicos (não da responsabilidade do governo) sobre medidas alternativas da actual política de austeridade implementada pelo governo. 
Os participantes não poupam críticas à actuação do governo e vão quase sempre no sentido de cortes no aparelho do Estado, designadamente na Assembleia da República, no funcionamento da Casa da Presidência da República, nos mil e um assessores dos ministérios e secretarias de Estado, na Caixa Geral de Depósitos, etc., etc., etc. esses sim serviços que forma o grosso das "gorduras do Estado" que o governo PSD-CDS erigiu em alvo predilecto, um pouco à imagem de D. Quixote a lutar contra os moinhos de vento.

Feitas as contas, lá onde há excessos bem quantificados deveria o governo ter procedido a cortes que, feitas as contas, davam bem para evitar os cortes nas pensões, na segurança social e no incentivo às actividades culturais e de ensino; pelo menos seria de boa gestão que a haver cortes eles se distribuíssem "pelas aldeias" e não só pelos grupos sociais mais desfavorecidos.

Concretamente, não seria aconselhável reduzir visivelmente o número de deputados e alguns privilégios dos funcionários da Assembleia da Republica? Será a Casa do Presidente da República tem direito a gastar uma verba superior à da Casa Real Espanhola? Será que os abonos para certas despesas de deslocação, subsídios de residência, de combustível, de telemóvel e não sei que mais, não deveriam ser controladas e nalguns casos suprimidos?

E o que se passa com as aquisições de viaturas de topo de gama e com as sucessivas nomeações de assessores com direito a vencimentos que as habilitações e experiência profissional dos nomeados não justificam, acrescidos de privilégios que foram suprimidos aos funcionários públicos (não dos ministérios)? Li numa das nomeações que aquele feliz contemplado tinha direito a catorze meses de vencimento, sem quaisquer descontos, sem cortes nos vencimento (como se aplicou a todo o funcionalismo)... e não sei que mais.

Não vale camuflar o direito ao subsídio de férias e de Natal com uma terminologia de substituição, fraudulenta por isso, uma vez que se reconhece a uns o direito que já se retirou a outros!

\section{d) A complexidade das relações internacionais}

A este nível se tem jogado o destino de grandes fatias das recitas e despesas do Estado. No entanto, não se trata aqui de enumerar casos de tratados. Convenções e meros contratos. Seria coisa fastidiosa e sempre incompleta.

Consideraria importante explanar situações não bem negociadas donde quase sempre resultaram consequências danosas para os interesses portugueses, isto porque o Estado assinou tratados bilaterais pouco atentamente, pondo inclusive algumas vezes de parte as questões relacionadas com a formalidade da outorga da independência aos antigos territórios nacionais, não esquecendo a questão da Índia. Embora essas questões se situem num tempo já longínquo, as situações não são uniformes e quase sempre os diversos governos se escudaram na tese de que Portugal negociou / reconheceu as ditas independências numa posição de fraqueza, versão que nunca foi consensual.

Passemos às questões mais recentes entre as quais é forçoso incluir aquilo que muito mexeu com a vida dos portugueses: o Tratado de Adesão à C. E. E. em 1995 e mais recentemente a entrada de Portugal no sistema monetário do euro. 
Em geral e em ambos os casos, aquilo a que se assistiu foi à aceitação submissa (era frequente ouvirmos dizer que nós «éramos bons alunos» da Europa porque se aceitaram de bom grado as cláusulas limitativas da nossa soberania e a supremacia das políticas europeias de desenvolvimento que nos impuseram obrigações pesadas e desajustadas à realidade da nossa situação económica.

Nem a nossa frágil economia (e todas as vertentes) foi protegida, nem as nossas actividades comerciais foram protegidas internacionalmente, nem sequer por alguns países da Europa, para não falar nos nossos vizinhos. Um exemplo mínimo de ausência de protecção adequada verificou-se na falta de reconhecimento internacional pela marca dos vinhos do Porto e os nossos governantes assobiarem para o lado... No entanto, souberam impor a exclusividade da marca francesa "Champagne" bem conduzida pelo governo francês, como se essa marca tivesse mais direitos que a marca portuguesa, mutatis mutandis. Só nos é aconselhado beber "espumante”, não é?

A quem atribuir a responsabilidade por tantos maus tratos? Não arrisco qualquer resposta!

E que dizer da participação no FMI e nas forças da NATO em ambos os casos em obediência cega à visão hegemónica dos Estados Unidos à qual a Europa se tem colado e submetido sem acautelar os interesses das populações e da condução de uma política ao serviço dos povos. Na prática, ignoram-se as contrapartidas que Portugal receberá (?) por integrar as forças militares dos diversos terrenos: países do Báltico, Iraque, Afeganistão, etc. Ou será que é a Europa que as recebe?

O povo português creio que deveria ser correctamente informado. Aquilo a que temos assistido quase sempre é ao fracasso total em relação aos objectivos prioritários internacionais da Europa colados aos dos Estados Unidos, sendo mais graves as consequências da participação activa na política da Líbia e da Síria, para não mencionar o atoleiro que resultou da última invasão do Iraque.

O mais recente exemplo de colagem situa-se na questão da Ucrânia, o que nos leva a perguntar o que é que nós temos a ver com as disputas entre os russos e os iraquianos? Será uma questão política, e qual?

Na nossa sabedoria popular há uma sentença que se repete nestas situações: "Quem está de fora, não racha lenha”. Cós diabos, não há por aí um português que nos represente? Portugal assim passa a ser corresponsável das consequências desastrosas das intervenções militares directas, ou indirectas em todo o Médio Oriente e no Norte de África e está também agora a braços com uma dessas resultantes: a chegada e acolhimento de muitas levas de refugiados vindos dessas zonas, aqueles refugiados em embarcações que já foram designadas por caixões flutuantes, dado que as pessoas chegam algumas vezes já falecidas.

Portugal terá também certamente responsabilidades na desestabilização dos países dessa área, de tal modo generalizada e grave que levou ao aparecimento de um autodenominado "Estado Islâmico" espalhado por dimensões fora do controlo da política internacional (da Península Ibérica ao Irão) naqueles moldes a que estávamos habituados pelos tratados internacionais; este Estado fundamenta-se em medidas limitadoras da liberdade como o Ocidente a considera; aplica a estrita doutrina islâmica com exclusão radical do pensamento greco-romano e judaico-cristão.

Trata-se sem dúvida de um desafio que só o futuro poderá melhor esclarecer, mas Portugal não se poderá escudar nas boas medidas e intenções da diplomacia europeia 
que tal como nas questões sociais e económicas está apta sim, mas para a aplicação e defesa dos seus próprios princípios directores.

Permitam-me ainda não me debruçar sobre a questão dos PALOP ( $\underline{\text { Países a a fro- }}$ -americano-asiáticos de língua oficial portuguesa: Portugal, Brasil, Guiné-Bissau, Cabo Verde, São Tomé e Príncipe, Angola, Moçambique, Timor leste e o recém-chegado Costa do Marfim): considero esse tema demasiadamente vasto e controverso, sobretudo porque a teia de relações entre os países lusófonos (há pelo menos um que não o é!) está pouco clara, digam o que disserem.

Oeiras, 11.06.2015 